\title{
Discussion of G. Dionne, "Adverse Selection and Repeated Insurance Contracts"
}

\author{
by Scott E. Harrington *
}

The developing literature on the economics of insurance markets with imperfect information has produced rather distressing results concerning the impact of asymmetric information on efficiency. The theory indicates that asymmetric information leads to a situation in which high risk consumers negatively affect the price-quantity menu of insurance contracts available to low risk consumers [Rothschild and Stiglitz, 1976; Wilson, 1977 ; Spence, 1978 ; and Hoy, 1982] with the possibility that some low risk consumers even may be driven from the market [Akerlof, 1970]. ** As noted by Professor Dionne in his interesting paper, the self-selection and risk classification mechanisms suggested in this literature may lead to Pareto improvements in welfare under certain conditions, but they do not eliminate inefficiency due to asymmetric information. Moreover, as emphasized by Rothschild and Stiglitz, a Nash equilibrium may not exist in markets with asymmetric information, and many unanswered questions remain with regard to market conditions that will result in a Wilson foresight-type equilibrium [Wilson, 1977].

Building on the work of Rubinstein and Yaari [1980] dealing with repeated insurance contracts and moral hazard, Professor Dionne's paper constitutes a valuable addition to the literature on insurance markets with asymmetric information since it demonstrates, albeit under strong assumptions, that a no-claims discount (or premium penalty) strategy exists that produces results that would occur with perfect information. No-claims discount and related prospective experience rating schemes in practice may primarily be used to provide incentives for claims control and to produce premium revisions consistent with new information on the consumer's loss potential rather than to provide incentives for truthful ex ante disclosure by consumers. The principal contribution of Professor Dionne's paper may be that it indicates that recontracting strategies or mechanisms may arise in a multiperiod setting that mitigate problems associated with asymmetric information. The paper should provide a basis for future analyses of the potential existence and viability of premium penalty and other recontracting mechanisms under weaker assumptions, such as competition among insurers and a finite time horizon with shifting loss probabilities for consumers.

\footnotetext{
* Assistant Professor of Insurance, University of Pennsylvania.

** References are provided in Professor Dionne's paper.
} 
Professor Dionne's analysis suggests several interesting questions concerning existing market and regulatory mechanisms that affect recontracting rights and decisions. The private passenger auto insurance market in the United States provides several convenient examples of such mechanisms that relate to the broad issue raised in Professor Dionne's paper : the potential existence of private market mechanisms that provide incentives for truthful disclosure of risk characteristics. For example, in most states auto insurers request information concerning an applicant's age, sex, marital status, driving territory, accident and violation record, as well as whether the applicant has had his or her insurance cancelled by another insurer, in order to determine whether to offer insurance and the price to be charged. While some of these characteristics are directly observable at little or no cost, the cost of verifying the accuracy of some information (e.g., territory and accident record; information concerning the latter variable that is provided by state motor vehicle departments is far from accurate in most states) may be such that ex ante verification is not cost-effective so that the insurer simply relies on the word of the applicant when deciding whether to issue a policy (or at least bind the insurance). Class-average ratemaking, state rate regulation, and competition all inhibit the use of premium penalties to promote thruthful disclosure. However, the right of insurers to cancel insurance and/or deny renewal (which may be restricted by state law, if not by competition) perhaps may be viewed as a mechanism that allows insurers to penalize applicants that fail to make truthful declarations concerning their risk. Moreover, the U.S. legal system generally allows insurers to deny payment for claims if the insured has not truthfully disclosed pertinent information requested by insurers. As a result, verification of information may become costeffective on an ex post basis. Theoretical analyses of the potential impacts of these two mechanisms for promoting truthful disclosure and their welfare effects would appear to be interesting areas for further research.

As noted by Professor Dionne, competition among insurers could effectively preclude the operation of the premium penalty mechanism suggested in the paper because consumers might be able to repeatedly make false disclosures and switch insurers to avoid penalties. Furthermore, even if insurers are able to obtain information concerning applicants' experiences with previous insurers to prevent repeated false disclosures, some insurers will be willing to write the bad risks at a profit, thus preventing operation of the penalty mechanism. Again with regard to the U.S. auto insurance market, it is interesting to note that consumers that have had their coverage cancelled frequently experience difficulty in obtaining coverage from other insurers at class rates, but may be offered coverage by so-called " nonstandard" insurers at higher premiums. Given Professor Dionne's analysis, the question arises as to whether denials of coverage by some insurers at their class rates may reflect reluctance to insure applicants that may have made false declarations in the past, given that they may be likely to do so again. The ability of consumers to purchase insurance from nonstandard insurers in many states is at least suggestive of competitive impediments to the type of incentive system suggested in the paper.

The fact that private mechanisms may exist that promote truthful disclosure, even if not fully effective, also has implications concerning regulatory policy. Regulatory restrictions on recontracting behavior obviously could interfere with and perhaps prevent the adoption of various strategies designed to promote truthful disclosure. For 
example, all states have enacted statutes that restrict insurer cancellation rights for private passenger auto insurance by limiting permissible reasons for cancellation, and several states have similar restrictions on insurer rights to deny renewal. The statutes in some states even prevent insurers from cancelling a policy on the basis of fraudulent statements by applicants after the policy has been in effect for sixty days. These statutes generally were enacted in the late 1960 s and early 1970 s in response to allegations of widespread capricious cancellations and the attendant difficulty for consumers to obtain coverage following cancellation. The question arises as to whether allegations of widespread cancellations and nonrenewals by insurers without substantive grounds could be consistent with the Rothschild-Stiglitz model of equilibrium, or the lack thereofe, in insurance markets with asymmetric information. If so, regulatory restrictions on insurer behavior in this regard might be viewed as responses to problems resulting from asymmetric information. However, it is not clear whether these restrictions would have the desired effect given the concept of a Wilson foresight equilibrium, since they would tend to restrict insurer responses to new contract offers by a particular insurer that were designed to attract low risk consumers. Viewed within the context of Professor Dionne's work, regulatory restrictions on recontracting rights of this type could be undesirable to the extent that they impede private mechanisms for promoting truthful disclosure.

Auto insurance residual market mechanisms in effect in all states that essentially require the private industry to provide insurance to all consumers (in many cases at rates that appear to be highly subsidized) who are not voluntarily insured in the private market provide another example of regulatory policy that may be related to the problem of asymmetric information. While the motivations and rationales for residual markets are undoubtedly complex, the potential ability of a high risk consumer to access the residual market independently of the accuracy of previous disclosure, perhaps at subsidized rates, clearly would tend to inhibit penalty mechanisms of the general type suggested by Professor Dionne.

Much additional research is needed concerning the effects and welfare properties of private market mechanisms and regulatory policies that may influence consumer incentives for truthful disclosure in insurance markets with asymmetric information. Professor Dionne's paper should provide both a basis and stimulus for further research in this area. 